Journal of Animal and Veterinary Advances 10 (13): 1743-1749, 2011

ISSN: $1680-5593$

(C) Medwell Journals, 2011

\title{
Evaluation of Bacteriocin Resistance in Staphylococcus aureus against the Bacteriocin Complex Secreted by Bacillus subtilis LFB112
}

\author{
${ }^{1,2}$ Bao-Sheng Liu, ${ }^{1}$ Gui-Guan Li, ${ }^{1}$ Zhan-Qiao Yu, ${ }^{1}$ Bing Han and ${ }^{1}$ Ri-Jun Zhang \\ ${ }^{1}$ Laboratory of Feed Biotechnology, State Key Laboratory of Animal Nutrition, \\ College of Animal Science and Technology, China Agricultural University, 100193 Beijing, China \\ ${ }^{2}$ College of Animal Science and Technology, Jiangxi Agricultural University, \\ 330045 Nanchang, China
}

\begin{abstract}
In order to pre-evaluate the possibility of bacteriocin resistance when utilizing a bacteriocin complex against pathogenic bacteria, Staphylococcus aureus was used to develop a resistant variant by stepwise method. The spontaneous frequency of $S$. aureus resistance to bacteriocin complex was about $10^{-5}$. The stability of resistant variant was confirmed by hundred successive transfers without bacteriocin complex stress. The growth rate of resistant variant was similar as that of its original strain. Interestingly in co-culture system, even inoculated with $90 \%$ of resistant variant, the resistant variant was cleared out by wild strain in eight consecutive transfers. When treated with either antibiotics or nisin, the resistant variant was more susceptible than the wild strain to all tested antimicrobial agents except chloramphenicol. However, only the tetracycline and chloramphenicol tested groups showed statistically significant increase and decrease of antibacterial potency $(\mathrm{p}<0.05)$, respectively. The cellular membrane fatty acid composition of resistant variant was similar to that of wild strain when cultured without bacteriocin complex suggested that the alterations of membrane fatty acid composition in resistant variants might not be the primary defense against bacteriocin. It is proposed that the bacteriocin complex can be used in animal disease preventions and therapeutics as an alternative or complement to traditional antibiotics.
\end{abstract}

Key words: Bacteriocin-resistance, Staphylococcus aureus, fitness cost, fatty acid composition, antibiotic alternative, China

\section{INTRODUCTION}

In recent decades, the dramatic rise in antibiotic resistant pathogens has renewed efforts to identify, develop and redesign antibiotics. It is already obvious that the current known antibiotics and possible derivatives will sooner or later lose their efficiency (Dubin et al., 2005). Therefore, the search for novel antimicrobial agents is of great value.

Bacteriocins, a category of antimicrobial bactericidal peptides, ribosomally synthesized by bacteria, exhibited a high bactericidal potency in almost all species of pathogens and a low toxicity to human and animals (Abdi-Ali et al., 2004; Mota-Meira et al., 2000). Thus, they represent potential alternatives or complements to conventional antibiotics in the treatment of infections (Asaduzzaman and Sonomoto, 2009; Hammami et al., 2010; Parisien et al., 2008). According to Klaenhammer (1993), Bacteriocins produced by gram-positive bacteria can be divided into three main classes based on their chemical and genetic properties. The first class is referred to as lantibiotics and nisin was the most studied one. The second class includes small heat stable bacteriocins such as pediocin PA-1. The 3rd group comprises large heat labile bacteriocins such as helveticin $\mathrm{J}$.

However, the bacteriocin resistant variants were generated experimentally in many laboratories. In fear of bacteriocins following the same step of antibiotics, researchers became more and more concerned with bacteriocin resistance. Previous data showed that the frequency of spontaneous bacteriocin resistance varied randomly from 10-9-10-2 (Gravesen et al., 2002; Guinane et al., 2006). Frequently, the acquisition of bacteriocin resistant variants increased their fitness costs despite an exception in some cases. Bacteriocin resistance was reported to associate with the reduced expression of the mpt operon (Opsata et al., 2010), the positive charges on the cell wall and the composition of fatty acids and

Corresponding Author: Ri-Jun Zhang, Laboratory of Feed Biotechnology, State Key Laboratory of Animal Nutrition, College of Animal Science and Technology, China Agricultural University, No. 2 Yuanmingyuan West Rd., Haidian District, 100193 Beijing, China 
phospholipids in the cell membrane (Jasniewski et al., 2008; Vadyvaloo et al., 2004a). All these studies were mainly focused on the food bio-preservatives while few were concerned on the risk of bacteriocin resistance when bacteriocins were used in animal disease treatment (Kirkup, 2006). We previously reported that Bacillus subtilis LFB1 12 producd a bacteriocin-like substance with a broad inhibitory spectrum of both gram-positive and negative pathogenic bacteria including Escherichia coli, Salmonella pullorum, Pseudomonas aeruginosa, Pasteurella multocida, Clostridium perfringens, Micrococcus luteus, Streptococcus bovis and Staphylococcus aureus (Xie et al., 2009). This antimicrobial substance presented a potential application in producing a bacteriocin veterinary medicine. Further investigation demonstrated that this bacteriocin-like substance was a complex composed of a bacteriocin of 47 amino acid residues (AIKLVQSPN GNFAASF VLDGT KWIFKSKYYDSSKGYW VGIYEVW D RK) and several other bacteriocin-like substances (data unpublished). In this study, trials were conducted to investigate the bacteriocin resistance against the bacteriocin complex with the use of Staphylococcus aureus as the pathogenic bacterium.

\section{MATERIALS AND METHODS}

Bacterial strains and culture conditions: Bacillus subtilis LFB112, the producer of bacteriocin complex was isolated from a Chinese herb by predecessors in the group. The optimized conditions to produce bacteriocin in a $50 \mathrm{~L}$ automatic fermentation system (GUJS-50, Zhenjiang East Biotech Equipment and Technology) were $30^{\circ} \mathrm{C}$, stirring at 180 rounds per minute, ventilating vigorously with filtrated sterile air and using a Landy medium (Landy et al., 1948).

Staphylococcus aureus IVDC C56005 (here-in-after referred to as SA), obtained from China Veterinary Culture Collection Center and grown aerobically at $37^{\circ} \mathrm{C}$ in nutrient broth/agar was the indicator bacterium used in the bacteriocin activity determination.

Resistant Staphylococcus aureus (here-in-after referred to as RSA), developed from SA was grown under the same condition as SA.

Bacteriocin complex preparation: All the bacteriocin complex used in this study were produced in a batch using B. subtilis LFB1 12 cultivated in a $50 \mathrm{~L}$ automatic fermentation system (GUJS-50, Zhenjiang East Biotech Equipment and Technology) for $20 \mathrm{~h}$. The culture was harvested and filtered using a nanometer-filter system (Nanjing Kaimi Science and Technology) after the cells were removed by a ceramic filter system (Nanjing Kaimi Science and Technology). The concentrated liquor with bacteriocins was processed to fine powder by spray-drying forming the final bacteriocin complex. The product was kept in stock at $-20^{\circ} \mathrm{C}$ throughout the experiments.

Antimicrobial activity determination: The antimicrobial activity of bacteriocin complex was determined using the microdilution method described by Naghmouchi et al. (2007) replacing nutrient agar as culture media and SA as indicator bacterium. Antimicrobial activity was expressed in arbitrary units per milliliter $\left(\mathrm{AU} \mathrm{mL}^{-1}\right)$, using the formula $(1000 / 125) \times(1 / D)$ where, $D$ was the highest dilution causing inhibition of SA. The Minimum Inhibitory Concentration (MIC) was the lowest concentration of bacteriocin complex giving complete inhibition of growth in SA (optical density equal to that of blank). The microdilution assay was done in triplicate.

Bacteriocin resistance frequency determination: The spontaneous bacteriocin resistance frequency was determined referring to the procedure proposed by Watanabe et al. (1989). Briefly, a $10 \mu \mathrm{L}$ portion of each 10 -fold serial diluted SA culture (fresh grown on its early stationary phase) was spotted onto nutrient agar with bacteriocin complex at 4 times MIC. Plates seeded SA were incubated at $37^{\circ} \mathrm{C}$ for $20 \mathrm{~h}$. The values of colony forming unit per milliliter (cfu mL ${ }^{-1}$ ) were calculated from colony count giving up to 30 colonies per spot (in most cases were 10-20). The number of viable count in SA culture was checked simultaneously by standard plate count method. The resistance frequency was calculated using the formula: $\mathrm{fr}=\mathrm{cfur} / \mathrm{cfus}$ where, fr was resistance frequency, cfur was cfu $\mathrm{mL}^{-1}$ when SA grown in plates with bacteriocin complex and cfus was cfu $\mathrm{mL}^{-1}$ when SA grown in plates without bacteriocin complex. This test was done in triplicate and the resistance frequency was determined by the average of two independent experiments.

Bacteriocin-resistant variant generation and stability determination: resistant $S$. aureus was generated from SA by stepwise process (Naghmouchi et al., 2007) with $0.5,1$, $2,4,8$ and $16 \times \mathrm{MHC}$ bacteriocin complex in nutrient broth in series transfer cultures at $37^{\circ} \mathrm{C}$. The purity and identity of each transfer was confirmed by streak plate method. The strain overcoming bacteriocin complex stress at $16 \times \mathrm{MIC}$ was regarded as RSA in this study and cultured routinely in nutrient broth containing bacteriocin complex at $16 \times \mathrm{MIC}$. The stability of the resistant phenotype was tested by hundred generations of exponential growth without bacteriocin complex. 
Fitness cost examination: The growth rate of RSA was comparatively studied with SA without bacteriocin complex selection. Nutrient broths inoculated with about $5 \times 10^{7} \mathrm{cfu} \mathrm{mL}^{-1} \mathrm{SA}$ or RSA, respectively (adjusted to the same $\mathrm{OD}$ values) were incubated aerobically at $37^{\circ} \mathrm{C}$. Samples were collected at a $2 \mathrm{~h}$ intervals from $0-12 \mathrm{~h}$. OD values were measured at $600 \mathrm{~nm}$ using an ultraviolet spectrophotometer (UV-8500, Techcomp) and viable bacteria were checked using Plate count method simultaneously for each sample. All the samples were checked in duplicate and the results were the average of three independent experiments.

Competitiveness examination: A competitive experiment of RSA and SA was performed. RSA and SA were mixed on their logarithmic phase at a cell number ratio of $1 / 9,1 / 4$, $1 / 1,4 / 1$ and $9 / 1$ according to their OD value. Each co-culture system was started at a total cell number of about $5 \times 10^{7} \mathrm{cfu} \mathrm{mL}^{-}$in the absence of bacteriocin complex in nutrient broth. Ten further successive transfers of the culture with $9 / 1$ and $1 / 9$ of RSA/SA were made to follow up the growth competitiveness of RSA in the co-cultured situation. All cultures were examined their susceptibility by bacteriocin complex at $16 \times \mathrm{M \Pi C}$ using Agar well diffusion method described below.

Antimicrobial susceptibility determination: The susceptibility of RSA to different antimicrobial agents was determined by agar well diffusion assay. Four oxford cups were assembled symmetrically in each plate which was seeded about $10^{6} \mathrm{cfu}$ RSA cells. Each cup was filled with $100 \mu \mathrm{L}$ streptomycin sulphate, kanamycin sulphate, gentamicin sulphate, penicillin $\mathrm{G}$ sodium, ampicillin sodium, chloramphenicol, tetracycline, vancomycin hydrochloride, nisin and the bacteriocin complex, respectively. The concentrations were: antibiotics $0.01 \mathrm{~mol} \mathrm{~L}^{-1}$, nisin $1.25 \mathrm{~g} \mathrm{~mL}^{-1}$ and bacteriocin complex $64 \mathrm{AU} \mathrm{mL}^{-1}$.

The plates were incubated aerobically at $37^{\circ} \mathrm{C}$ for 18-20 h. Diameters of the inhibition zone were recorded to determine the susceptibility of RSA to the antimicrobial agents. SA was tested as a comparison with the identical procedure. This test was done in duplicate and the results were the average of three independent experiments.

Bacteriocin complex decomposition: About $10 \mathrm{~mL}$ bacteriocin complex was prepared at $16 \times \mathrm{MIC}$ using sterilized nutrient broth or normal saline prior to mixing with ca. $1.0 \times 10^{9}$ cfu RSA which was prepared with $11068 \mathrm{~g}$ centrifugation from fresh RSA culture. The bacteriocin complex (diluted by nutrient broth and normal saline) without RSA were made as control groups. Both 2 controls and two treatment mixtures were incubated at $37^{\circ} \mathrm{C}$ with vigorous shaking. Samples were collected from each control and treatment group at $2 \mathrm{~h}$ intervals from $0-8 \mathrm{~h}$. Antimicrobial activity of the mixture was examined using Agar well diffusion method described above post RSA removing by centrifugation at $11068 \mathrm{~g}$.

Membrane fatty acids composition analysis: RSA was grown in nutrient broth with or without bacteriocin complex, respectively and $\mathrm{SA}$ was grown without bacteriocin complex. Cells were collected on their early stationary phase by an $11068 \mathrm{~g}$ centrifugation. The pellets were washed three times with normal saline and lyophilized at $-50^{\circ} \mathrm{C}$. Cellular fatty acids were converted to methyl esters by acetyl chloride/methanol (1/9, volume in volume) solution using tightly jam-packed tubes with water bath at $80^{\circ} \mathrm{C}$ for $2 \mathrm{~h}$. The fatty acid methyl esters were extracted by toluene and analyzed using an Hp 6890 series system (Hewlett Packard) equipped with a DB-23 capillary column $(60 \mathrm{~m} \times 0.25 \mathrm{~mm}$; J and $\mathrm{W}$ scientific $)$. The temperature inside the column was initially maintained at $180^{\circ} \mathrm{C}$ for $10 \mathrm{~min}$ and then gradually increased to $250^{\circ} \mathrm{C}$ at a rate of $10^{\circ} \mathrm{C} \mathrm{min}^{-1}$ and finally held at $250^{\circ} \mathrm{C}$ for $6 \mathrm{~min}$. All samples were analyzed in triplicate and the result was the average of two independent experiments.

Statistical analysis: All the data acquired was statistically analyzed using SPSS Version 12.0. The significant difference between SA and RSA was compared using one-way ANOVA program. For all analysis, difference was considered significant at $\mathrm{p}<0.05$.

\section{RESULTS AND DISCUSSION}

Antimicrobial activity of bacteriocin complex: The antimicrobial activity of bacteriocin complex in the spraying powder product was $1024 \mathrm{AU} \mathrm{g}^{-1}$ and the $\mathrm{MIC}$ was $7.8 \mathrm{mg} \mathrm{mL}^{-1}$.

Spontaneous resistance frequency of SA and stability of RSA: The spontaneous resistance frequency of SA was $9.3 \times 10^{-6}$. RSA was developed from SA under the progressive selection (Fig. 1) and the stability of its resistant phenotype was confirmed by hundred successive transfers without selection.

Fitness cost and competitiveness of RSA: The specific growth rate of RSA was similar to that of SA in both viable count and $\mathrm{OD}$ value (Fig. 2 ). In co-culture system, RSA multiplied much slower than SA and remained the minority on stationary phase even inoculated at a RSA/SA cell ratio of 9/1. Moreover, RSA was replaced by SA gradually in eight successive transfers following up. 


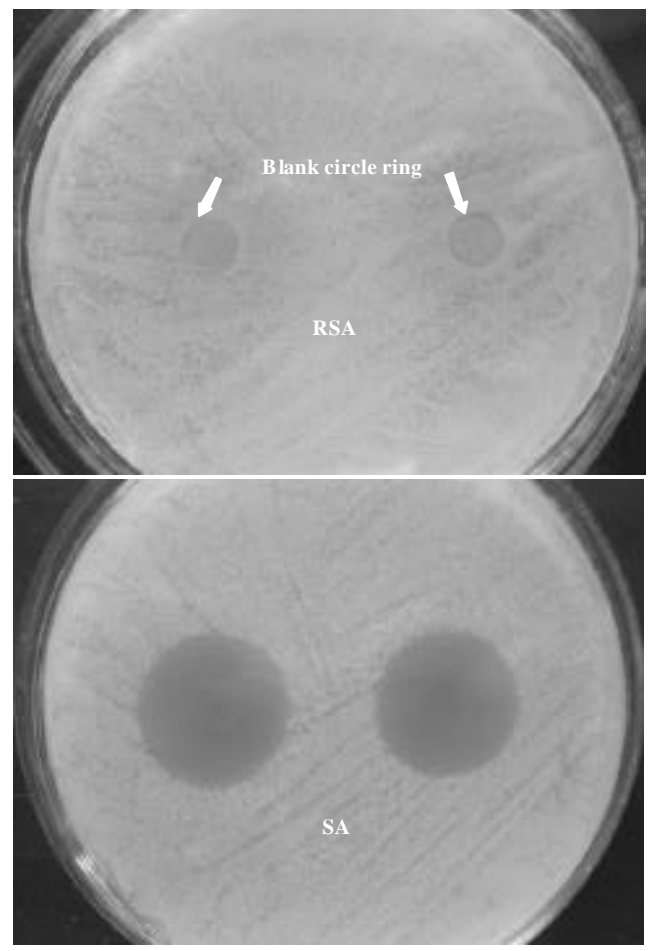

Fig. 1: Resistant $S$. aureus (RSA) was seeded ca. $10^{6} \mathrm{cfu}$ and challenged with $100 \mu \mathrm{L}$ bacteriocin complex at $16 \times \mathrm{MIC}$ using Agar well disffusion method. The blank circle ring on RSA was formed by the press of oxford cup. S. aureus (SA) was the comparison made with same procedure

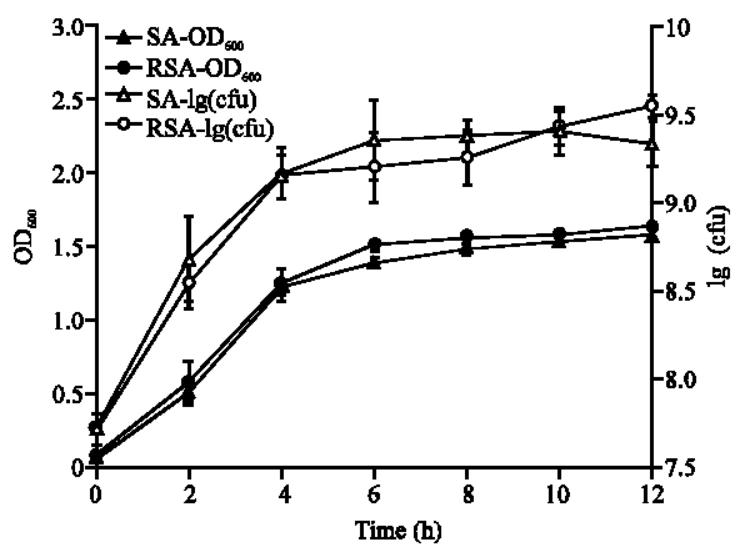

Fig. 2: The growth characteristics of $S$. aureus (SA) and Resistant $S$. aureus (RSA) cultured with vigorous shaking in nutrient broth at $37^{\circ} \mathrm{C}$ in the absence of bacterion complex

Antimicrobial susceptibility of RSA: SA was sensitive to all antimicrobial agents and RSA was completely resistant to the bacteriocin complex as presumed (Fig. 3). Seven out of eight antibiotics tested in this study improved their

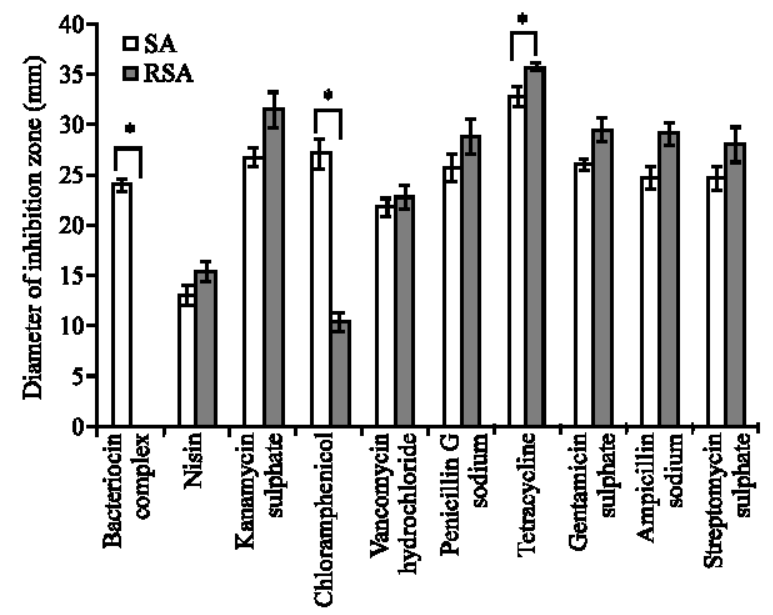

Fig. 3: Antimicrobial susceptibilities of S. aureus (SA) and Resistant S. aureus (RSA) checked with $100 \mu \mathrm{L}$ antibiotics $\left(0.01 \mathrm{~mol} \mathrm{~L}^{-1}\right)$, nisin $\left(1.25 \mathrm{~g} \mathrm{~mL}^{-1}\right)$, bacteriocin complex $(16 \times \mathrm{MIC})$, respectively using Agar well diffusion method. *Significant difference $(p<0.05)$ was presented between RSA and SA

antibacterial potency to RSA and tetracycline demonstrated a significant $(\mathrm{p}<0.05)$ change when they were compared to that of SA. Unfortunately, chloramphenicol shrank the inhibition zone significantly $(p<0.05)$ when the bacterium developed resistance of bacteriocin complex from SA to RSA.

Bacteriocin complex decomposition and membrane fatty acids composition: In the mixture of RSA and the bacteriocin complex, RSA did not attenuate the antimicrobial activity of bacteriocin complex either incubated in normal saline or nutrient broth.

The mass content of fatty acids was significant increased in $\mathrm{C} 18: 3(\mathrm{p}<0.05)$ and decreased in $\mathrm{C} 20: 0$, $18: 0$ and 14:1 $(\mathrm{p}<0.05)$ in RSA cultured with bacteriocin complex selection as compared with RSA cultured without bacteriocin complex. However, the fatty acid constituent of SA and RSA cultured in the absence of bacteriocin complex appeared similar ( $>0.05$, Table 1).

Recently, superbugs with NDM-1 which was mostly found among Escherichia coli and Klebsiella pneumonia (Kumarasamy et al., 2010) have killed several human lives and fatal cases continue to occur all over the world. The situation that the speed of developing novel antibiotics is much slower than the rate at which pathogens acquire resistance makes the development of alternative therapeutic strategies a burning necessity. Bacteriocins targeting the membrane with their observed diversity and proven effectiveness, provide a very promising approach worthy of development in animal disease control. 
Table 1: Cellular fatty acids composition of $S$. aureus and its resistant variant grown in nutrient broth with or without bacteriocin complex $\left(\mathrm{mg} \mathrm{g}^{-1}\right)$

\begin{tabular}{|c|c|c|c|}
\hline \multirow[b]{2}{*}{ Bacteriocin complex } & \multirow{2}{*}{$\begin{array}{l}\text { S. aureus } \\
0 \mathrm{MIC} \\
\end{array}$} & \multicolumn{2}{|c|}{ Resistant $S$. aureus } \\
\hline & & $0 \mathrm{MIC}$ & $16 \mathrm{MIC}$ \\
\hline $\mathrm{C} 14: 0$ & $0.181 \pm 0.037$ & $0.199 \pm 0.080$ & $0.124 \pm 0.001$ \\
\hline C14:1 & $1.438 \pm 0.164^{\mathrm{AB}}$ & $2.051 \pm 0.385^{\mathrm{A}}$ & $1.114 \pm 0.025^{\mathrm{B}}$ \\
\hline $\mathrm{C} 16: 0$ & $1.705 \pm 0.212$ & $1.869 \pm 0.536$ & $1.856 \pm 0.158$ \\
\hline C16:1 & $0.034 \pm 0.009$ & $0.047 \pm 0.037$ & $0.040 \pm 0.004$ \\
\hline $\mathrm{C} 18: 0$ & $3.143 \pm 0.183^{\mathrm{AB}}$ & $3.959 \pm 0.583^{\mathrm{A}}$ & $2.402 \pm 0.104^{\mathrm{B}}$ \\
\hline C18:1n9 & $0.419 \pm 0.061$ & $0.338 \pm 0.088$ & $0.263 \pm 0.009$ \\
\hline C18:2n6 & $0.126 \pm 0.032$ & $0.083 \pm 0.016$ & $0.044 \pm 0.021$ \\
\hline C18:3n3 & $0.106 \pm 0.026^{\mathrm{A}}$ & $0.115 \pm 0.025^{\mathrm{A}}$ & $0.288 \pm 0.019^{\mathrm{B}}$ \\
\hline $\mathrm{C} 20: 0$ & $4.420 \pm 0.240^{\mathrm{A}}$ & $4.608 \pm 0.381^{\mathrm{A}}$ & $2.550 \pm 0.072^{\mathrm{B}}$ \\
\hline $\mathrm{C} 20: 1$ & $0.279 \pm 0.046$ & $0.271 \pm 0.042$ & $0.140 \pm 0.001$ \\
\hline $\mathrm{C} 22: 0$ & $0.068 \pm 0.028$ & $0.049 \pm 0.035$ & $0.128 \pm 0.108$ \\
\hline
\end{tabular}

Cells of S. cureus (SA) and Resistant S. cureus (RSA) were harvested and lyophilized on their early stationary phase. Fatty acids were extracted and analyzed by converting to methyl esters with acetyl chloride/methanol (1/9 volume) solution using Gas chromatography method. Data were acquired from two independent experiments. Different superscript in the same line means significant difference $(\mathrm{p}<0.05)$

However, more studies were required to ensure the safeties and low risks of bacterial resistance in the application of bacteriocins. In this study, bacteriocin resistance to the bacteriocin complex was observed occurring at a frequency of $9.3 \times 10^{-6}$ in SA. RSA was generated and the stability of its resistant phenotype was confirmed by hundred successive generations without bacteriocin complex.

The result that the specific growth rate of RSA was similar to that of SA was consistent with results from Sakayori et al. (2003) but contrary to those that the resistant variant had fitness costs in reducing specific growth rate (Vadyvaloo et al., 2004b).

In order to assess the potential spread of RSA in natural populations of SA, RSA was competed with SA in co-culture systems. The dwindlement of RSA in all co-cultures illustrated that RSA was weaker than SA when they grew together. Furthermore, the replacement by $\mathrm{SA}$ in co-culture with $90 \%$ inoculum of RSA demonstrated that RSA would be eventually cleaned out by SA when bacteriocin complex was not present. When challenged with antimicrobial agents, RSA became more susceptible than SA to nisin and all tested antibiotics except chloramphenicol, however only the decrease of chloramphenicol antimicrobial potency and the increase of tetracycline antimicrobial potency were statistically significant $(p<0.05)$. These observations displayed the controversial situation of inter-functions between bacterions and antibiotics in treatment of bacteriocin resistant bacteria. Duffes et al. (2000) reported that bacteriocin resistance did not confer any resistance to penicillin, amoxicillin, vancomycin, rifampin, kanamycin, chloramphenicol, erythromycin, gentamicin or tetracycline. On the contrary, Naghmouchi et al. (2007) declared that all bacteriocin resistant variants were more resistant to ampicillin, chloramphenicol, vancomycin and kanamycin than that of its original strain. Actually, crossresistance between bacteriocin and antibiotics or inter bacteriocins might be primarily decided by the physiological characteristics of resistant variants and the targets that antimicrobial agents act on.

The increased resistance to antibiotics may indicate that the compositional changes in the cell of variants selected by exposure to bacteriocin can also confer protection to other inhibitory substances such as antibiotics. By the same token, the resistance to a bacteriocin may extend to other bacteriocins within the same class or even in other classes (Draper et al., 2009). Cross-resistance of bacteria to a bacteriocin is an intrinsic characteristic and no clear correlation has been established between the bacteriocins and antibiotics. In order to investigate the possible mechanisms of RSA resistance, bacteriocin complex was incubated with RSA in normal saline solution or nutrient broth at $37^{\circ} \mathrm{C}$. Both groups illustrated identically that RSA had no effect on the activity of bacteriocin complex.

In other words, the components of bacteriocin complex were not decomposed by intracellular or extracellular enzymes of RSA. Based on this precondition, we inferred that the reason why RSA resisted to the bacteriocin complex was that RSA escaped from the influence of the bacteriocin complex instead of diminishing its activity. Therefore, we analyzed the cellular fatty acid composition which was supposed to confer the resistance property of RSA. Surprisingly, there was no difference in fatty acid composition between RSA and SA when they were cultured in media without bacteriocin complex. Therefore, it suggested that the resistance of RSA was not due to the change of cellular membrane fatty acids. However, the increase of C18:3 and decrease of C20:0 were significant in RSA which was cultured with bacteriocin complex as compared to RSA and SA which were cultured without bacteriocin complex. These results illustrated that variation of membrane fatty acids was not the factor that induced RSA resistance but the outcome of additional bacteriocin complex.

The mechanism of resistance to bacteriocins has been correlated with changes in membrane fatty acid and phospholipid composition, cell wall structure and requirements for divalent cations. The increased proportion of saturated fatty acids in the bacteriocinresistant variants should increase membrane rigidity rendering it less fluid and thereby impeding penetration by bacteriocin molecules (Naghmouchi et al., 2007). On the other hand, an increase in short-acyl-chain and unsaturated phosphatidylglycerol in resistant strains 
indicated greater fluidity of the cell membranes, thus also increasing the resistance of mutant variaties (Vadyvaloo et al., 2004a). In the study, the fatty acid composition was similar between SA and RSA when cultured without bacteriocin complex but significantly different in some fatty acids of RSA when cultured with bacteriocin complex. The result was consistent with Limonet et al. (2002). These results suggested that the alterations of membrane fatty acid composition in resistant variants might not be the primary defense against bacteriocin.

\section{CONCLUSION}

RSA can not be spread out in reality due to its weaker competitiveness to SA when they grow together. The difference of fatty acid composition was induced by bacteriocin complex nevertheless, it was not the cause of resistance in RSA. Cross-resistance inter-bacteriocins or between bacteriocin and antibiotics is a characteristic that requires further studies of resistant strains. It is proposed that bacteriocins can be used in animal disease preventions and therapeutics as an alternative to antibiotics which were serious in high and/or multi-resistance of bacteria for the moment.

\section{ACKNOWLEDGEMENT}

This research was financially supported by National High Technology Research and Development Program of China (863 Program), grant no. 2006AA10A208. Bao-Sheng Liu and Gui-Guan Li contributed equally to this work.

\section{REFERENCES}

Abdi-Ali, A., E.A. Worobec, A. Deezagi and F. Malekzadeh, 2004. Cytotoxic effects of pyocin S2 produced by Pseudomonas aeruginosa on the growth of three human cell lines. Can. J. Microbiol., 50: $375-381$.

Asaduzzaman, S.M. and K. Sonomoto, 2009. Lantibiotics: Diverse activities and unique modes of action. J. Biosci. Bioeng., 107: 475-487.

Draper, L.A., K. Grainger, L.H. Deegan, P.D. Cotter, C. Hill and R.P. Ross, 2009. Cross-immunity and immune mimicry as mechanisms of resistance to the lantibiotic lacticin 3147. Mol. Microbiol., 71: 1043-1054.

Dubin, A., P. Mak, G. Dubin, M. Rzychon and J. StecNiemczyk et al., 2005. New generation of peptide antibiotics. Acta Biochim. Pol., 52: 633-638.
Duffes, F., P. Jenoe and P. Boyaval, 2000. Use of twodimensional electrophoresis to study differential protein expression in divercin V41-resistant and wildtype strains of Listeria monocytogenes. Applied Environ. Microbiol., 66: 4318-4324.

Gravesen, A., A. A. Jydegaard, S. J. Mendes, T.B. Hansen and S. Knoche1, 2002. Frequency of bacteriocin resistance development and associated fitness costs in Listeria monocytogenes. Applied Environ. Microbiol., 68: 756-764.

Guinane, C.M., P.D. Cotter, C. Hill and R.P. Ross, 2006. Spontaneous resistance in Lactococcus lactis IL1403 to the lantibiotic lacticin 3147. FEMS Microbiol. Lett., 260: $77-83$.

Hammami, R., A. Zouhir, L.C. Le, H.J. Ben and I. Fliss, 2010. BACTIBASE second release: A database and tool platform for bacteriocin characterization. BMC Microbiol., 10: 22-22.

Jasniewski, J., C. Cailliez-Grimal, M. Younsi, J. Milliere and A. Revol-Junelles, 2008. Functional differences in Leuconostoc sensitive and resistant strains to mesenterocin 52A, a class IIa bacteriocin. FEMS Microbiol. Lett., 289: 193-201.

Kirkup, B.C., 2006. Bacteriocins as oral and gastrointestinal antibiotics: Theoretical considerations, applied research and practical applications. Curr. Med. Chem., 13: 3335-3350.

Klaenhammer, T.R., 1993. Genetics of bacteriocins produced by lactic acid bacteria. FEMS Microbiol. Rev., 12: 39-85.

Kumarasamy, K.K., M.A. Toleman, T.R. Walsh, J. Bagaria and F. Butt et al., 2010. Emergence of a new antibiotic resistance mechanism in India, Pakistan, and the UK: A molecular, biological and epidemiological study. Lancet Infect. Dis., 10: 597-602.

Landy, M., G.H. Warren, S.B. Rosenman and L.G. Colio, 1948. Bacillomycin: An antibiotic from Bacillus subtilis active against pathogenic fungi. Proc. Soc. Exp. Biol. Med., 67: 539-541.

Limonet, M., A.M. Revol-Junelles and J.B. Milliere, 2002. Variations in the membrane fatty acid composition of resistant or susceptible Leuconostoc or Weissella strains in the presence or absence of Mesenterocin $52 \mathrm{~A}$ and Mesenterocin 52B produced by Leuconostoc mesenteroides subsp. mesenteroides FR52. Applied Environ. Microbiol., 68: 2910-2916.

Mota-Meira, M., G. Lapointe, C. Lacroix and M.C. Lavoie, 2000. MICs of mutacin B-Ny266, nisin A, vancomycin and oxacillin against bacterial pathogens. Antimicrob. Agents Chemother., 44: 24-29. 
Naghmouchi, K., E. Kheadr, C. Lacroix and I. Fliss, 2007. Class I/class IIa bacteriocin cross-resistance phenomenon in Listeria monocytogenes. Food Microbiol., 24: 718-727.

Opsata, M., I.F. Nes and H. Holo, 2010. Class IIa bacteriocin resistance in Enterococcus faecalis V583: The mannose PTS operon mediates global transcriptional responses. BMC Microbiol., 10: 224-224.

Parisien, A., B. Allain, J. Zhang, R. Mandeville and C.Q. Lan, 2008. Novel alternatives to antibiotics: Bacteriophages, bacterial cell wall hydrolases and antimicrobial peptides. J. Applied Microbiol., 104: 1-13.

Sakayori, Y., M. Muramatsu, S. Hanada, Y. Kamagata, S. Kawamoto and J. Shima, 2003. Characterization of Enterococcus faecium mutants resistant to mundticin KS, a class Ila bacteriocin. Microbiology, 149: 2901-2908.
Vadyvaloo, V., J.L. Snoep, J.W. Hastings and M. Rautenbach, 2004a. Physiological implications of class IIa bacteriocin resistance in Listeria monocytogenes strains. Microbiology, 150: 335-340. Vadyvaloo, V., S. Arous, A. Gravesen, Y. Hechard, R. Chauhan-Haubrock, J.W. Hastings and M. Rautenbach, 2004b. Cell-surface alterations in class IIa bacteriocin-resistant Listeria monocytogenes strains. Microbiology, 150: 3025-3033.

Watanabe, M., M. Inoue and S. Mitsuhashi, 1989. In vitro activity of amifloxacin against outer membrane mutants of the family Enterobacteriaceae and frequency of spontaneous resistance. Antimicrob. Agents Chemother., 33: 1837-1840.

Xie, J.H., R.J. Zhang, C.J. Shang and Y.Q. Guo, 2009. Isolation and characterization of a bacteriocin produced by an isolated Bacillus subtilis LFB112 that exhibits antimicrobial activity against domestic animal pathogens. Afr. J. Biotechnol., 8: 5611-5619. 